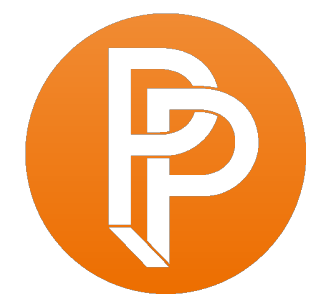

PERFORMANCE

PHILOSOPHY

\title{
'THE SHADOW OF ONE'S OWN HEAD' OR THE SPECTACLE OF CREATIVITY ${ }^{1}$
}

\section{SUSANNE VALERIE GRANZER UNIVERSITY OF MUSIC AND PERFORMING ARTS VIENNA, MAX REINHARDT SEMINAR \\ Translation from German to English: Mirko Wittwar}

Body on Stage

The relation between actor/actress and audience is extremely complex. Furthermore, it is different each time, as each performance is unique as such. In each case there develops a multi-layered relation, a kind of assemblage with a variety of connective and disjunctive relations. In the course of the performance these relations develop between actors/actresses and audience as well as between the actors/actresses on the stage. Just the same, however, within each actor/actress there develops an extended network of differential references, which is a precondition for successful acting. This process might be called artistic research or, to have it in the language of theatre, the research and investigation of the layers and stories of the characters which must be seen, understood and updated, i. e. they must be made visible.

This text is supposed to focus on an event taking a successful performance to its extremes, when it comes to its poignancy. This may indeed be equated with a spectacle. This is to say that, by acting on stage, the position of the subject is put into question. It is deprived of its priority, of its firstperson position, of its safe harbour. The sovereign subject is deprived of its power. It loses its crown which falls on its own feet. This may be read as a kind of destabilisation or even a narcissistic humiliation of the ego. At the same time this displacement contradicts itself. Is it not that it is the crucial event of creativity? The heart of the performing arts, beyond their aesthetic formats? Is it 
not that at the same time it concerns and does not concern the sensual experience of actors/actresses as well as the increased perception of the audience, as time goes by in a flash while standing still at the same time? This "death of the subject" may cause joy, however also the contrary. For it is an event going beyond the level of pure entertainment, beyond the sheer gesture of representation-and by acting suddenly a non-representative power of art has effect which the actors/actresses experience as being at the mercy of. By this turn, on the one hand acting starts this wonderfully easy floating by which it becomes surprisingly enriched and which cannot be created at will but must come by itself, like sleep which also cannot be commanded at will. On the other hand, it pulls the familiar rug out from under the participants' feet, as it might be described.

Being an actress, I look back to practical experience with theatre, and my own experiences on stage have always urged and driven me to ask and to perhaps find out more about what happens by the complex process of acting on stage from a philosophical point of view.

Actors/actresses-this is obvious - work with themselves as the medium of their art. Thus, by them it becomes particularly visible that, as artists, they depend on all sensual and intellectual capabilities and performances of their human existence. For this is exactly what they are working with, one to one. By listening, watching, speaking, answering, walking, existing together with others, by understanding, thinking, assessing and creating references. Updating all these levels by their own and most extreme potentials and, to have it perhaps even more fundamentally, learning them once again, counts among the tasks of theatre. A challenging, relentless work, meaning primarily cultivation and forcing on but not ruling, dominating. Furthermore, seen from the outside it is a kind of work which is mostly underestimated.

It is one of the crucial experiences of acting on stage that there is no fundamental difference between mind and matter. ${ }^{2}$ Neither is the mind inferior to the body nor is the body superior to the mind. There is no hierarchy. Both are given preconditions as well as equipment for successful acting. If an actor/actress, consciously or unconsciously, attempts to ignore or manipulate the material or spiritual conditions of his/her own body, his/her acting will be below his/her best. $\mathrm{He} /$ she must give up on his/her own will while at the same time being most attentive. In other words, he/she must deliver him/herself and cooperate with him/herself. In this process the spiritual and the physical substance are permanently interplaying, they are given entities in time and space. They cannot be separated. On stage, prejudices or hostility towards them result in a draw. However, these processes are much easier described than made happen on stage. We have incorporated the separation of mind and matter much more than we are aware of and thus our specific relation to them. This is clearly unmasked by the stage. 
Practical experiences on stage demonstrate unmistakably that mind and matter form a union. One might compare them to Siamese twins. They cannot be isolated, except they are taken violently apart from each other, which way both will be damaged. An actor/actress cannot and may not try to invalidate this fact, for he/she is not only tied to both but, even more, he/she his/herself Is both: mind AND matter. A dual interpretation of mind and matter does not work with theatre. This is why the stage does not know any ascetic ideal, any neutralisation of desire which after all still secretly and unconsciously has its say in the cellars of bodiliness. So to speak as an imaginary prompter with the textbook of the respective story in his/her hands, whispering it to the person on stage. However, declaring mind and matter one and the same would be a misunderstanding. Also, when working on stage sometimes rather "consciousness" and then again "intuition" must be in charge, and it is evident that each of them has its own quality and intelligence, allowing for their own specific ways of perceiving and understanding in each case. This is what actors/actresses must learn to differentiate for their art. They are urged to discover the different potentials of the different powers, to be able to work with them, always themselves being the subject of the play of these forces. With themselves as the guinea pigs. However, not with a rabbit pulled out of the hat but with one which means business when researching itself, this research, by the way, not happening once, that is once and for all, but being renewed and becoming ever more thorough with each rehearsal process and each performance. In this context, wanting to play the role of controller observing his/her own acting from the watchtower proves to be a dead-end. This does not work and will only be counterproductive.

Of course, all artistic work is based on skilled craftsmanship (téchne) which is and must be learned, practiced, exercised, known and finally purposefully used. Uncontrolled acting is not only unprofessional but may be fatal. It does not bear contemplating. Of course, an actor/actress is always aware that he/she is acting, and each production consists of a great number of agreements which require to be kept. At the same time, however, these agreements need leeway, leeway for free acting, where each repetition becomes lively and unique. Repetitions should never be mechanic, just a technique, that is a stereotype. In such a case they would be empty and uninspired, just the reeling off of a programme, without groove, without flow and, to have it this way: unanimated. In the course of the process, again and again one and the same challenge and difficulty becomes obvious: what happens cannot be fully controlled. Each time it must turn out well. Having been successful one time does not necessarily mean to be successful the next time. It may be that the boulder has been rolled up the hill in vain. All efforts have been futile. Sisyphus says hallo from Hades. But also Apollo from Olympus, if acting has been a success.

This image from Hades is supposed to be an attempt to illustrate that on stage the act of willing is not sufficient for making acting successful, as the interpretation of the subject being the sole actor of what it does is invalidated by the creative act on stage. For the controller, to have it in the language of theatre, this means "exit", and to have it even more pointedly: the actor's/actress's ego must simply "shut up". This is meant to say that it must give up on its control function, of its predominant position. Then, in the process of acting, body and mind will be enabled to encounter 
each other on the thorough basis or artistic craftsmanship, by fruitful dispute and by lustfully quarrelling for the best possible solution for working together. The more intensively both are affirmatively connected in the process, the more they welcome each other as a community of friends, the more happily Eros is included, the better the effect for the entire situation on stage. Establishing a hierarchy of mind and matter and declaring them not partners with equal rights but antagonists is fatal. When acting, not listening to one's body, for example, not giving in to its stimulations, declaring it a disturbing factor, that is declaring it a troublemaker ${ }^{3}$-as it is suggested by the autonomy of the subject-results in a number of useless and unpleasant problems. Body and mind will block each other, and as a consequence they will lose the power of their potential and imagination. That is why the intimate relation of body and mind in the context of the artistic challenge is crucial for a successful performance-and results in an astonishing increase of pleasure for the actors/actresses.

\section{Criteria for Creativity}

Thus, the artistic process on stage makes issues of existence move. Issues in the general sense of our existence. The phenomena and problems of our conditio humana within which we find ourselves and to which we are exposed are really imposed on us in the process of acting. They can neither be excluded nor manipulated nor ignored without acting losing its lively creativity. All those many levels of our existence are the playground, and the radical aspects of theatre. This is the particular fate of this most anthropological of all arts. Its offer and its threat. Indeed, actors/actresses are immediately confronted with themselves as their own medium. Explicitly and obviously they must work with and contribute to the conditions of their human existence, from which they gain the shape of their character, from which they chisel the sculpture of their work. This requires much sensitivity and power and exposes us to a permanent process not knowing any standstill and never coming to an end once and for all. The courses of this process reveal a complex system of signs in the body, the mind, the mood and the gender which may neither be suppressed nor ignored but must be faced by actors/actresses while working with it openly. Thus, a role is never completed once and for all. Acting develops over time and passes in time. In a moment. It cannot be grasped, it does not become manifest by any object. It is always tied to making it happen again, which may always become a failure. On the other hand, it always allows for a beginning, for a fresh start, for another try. Just the same, the capability of starting again is an integral element of acting. If it fails, it may well be that it will be a success the next time, it may even become something grandiose. If, however, in terms of anthropology actors/actresses leave behind their particular talents in the dressing room after the performance or not is a different question.

All these sensitive, sensual events always happen in front of other people, it may be during rehearsals in front of the team or during the performance in the front of the audience. Acting without a safety net, as we have it at theatre. Thus, the significance of what it means for actors/actresses to always being immediately exposed to others during the intimate event of their artistic work may not be belittled. Or, to have it positively, perhaps it is also an inspiration for them. 
In any case, always there are others present, watching them while they are not able to watch themselves. They never know what they are looking like from the outside. They always depend on the response of those others, including all ambivalences connected to it. One's own art being publicly exposed to the permanent risk of becoming results in great fragility. On the other hand, and as a protection, it may be that this is the reason for the striking extrovertedness or even eccentricity of many actors/actresses. Thus, to understand the performing arts it is crucial to understand that actors/actresses, in the name of creativity, are always exposed and stay exposed to a dynamic ground. To have it differently, acting on stage is never a once and for all closed entirety. It is and stays to be a promise of becoming. At any rehearsal, at any performance, again and again and again. Actors/actresses must bear this process of constant becoming, must voluntarily entrust themselves to it, and this also means giving up on the understandable wish for security. Concerning their art, they are and stay to be subject to the promising, however also frightening fate of constant change. This challenge cannot be skipped. In other words, they must give up on wanting to be a sovereign subject, as we would like to believe, and must accept that their art intensively oscillates between active and passive, always on the threshold of a never-ending process, always being entangled in many differentiated relations to others they cannot control. One out of many. Being permanently exposed to others, bodily, sensitively, physically. They can never be sure about what might have been happening. The dynamic of becoming is always at work. Acting is an ephemeral kind of art, and no medium is capable of reflecting it appropriately.

To once again summarise the process of being as becoming on stage: As the crucial event of creativity when acting multi-sensorially on stage, a break has been described which may happen to an actor/actress. The "death of the subject". It is this what suddenly makes him/her experiencenot reflectively, not intellectually, but sensually, bodily-the giving up on the inherited, incorporated illusion of being "the actor, the subject" of "his/her own performance." 4 Simultaneously there appears a zone of incapability to distinguish being active from being inactive, agent from patient (Agamben 1999a, 235). The actor/actress acts while not acting at the same time. $\mathrm{He} / \mathrm{she}$ is both actor and non-actor-and precisely this strange pathos makes a performance an event. This ambivalent, artistic experience catapults those involved into an open in-between, into an irritating passage of being with-out-me. It is evident that there must be some-body who acts, however the contradictory condition for making a performance an event is that no-body acts. That is, there happens a process requiring an actor while not requiring an actor. This is an irritating fact leading a life of its own and not being controllable. What happens to me at this threshold, to my self, to myself as a person beyond reason and reflection? What does it mean for my free will, what happens to my autonomy? To my sovereignty? What happens to me when being permanently exposed to others, in this shared field to which I am obviously exposed and stay to be exposed?

We have incorporated the ideas of the Enlightenment much more than we are usually aware of. The metaphysics of the subject with its illusions of identity and sovereignty work like a machine beyond awareness, and we are sitting in the cave of our perception, watching the shadows of our heads. 
Seen this way, being as becoming on stage creates a gap within man. This gap may have a frightening or constrictive effect, like a pressure or a burden. Or, on the contrary, like a promising openness. Then it will change from being fate to being the quality of beginning which does fade over time and finds expression by the power of creativity.

\section{Becoming}

In so far, the creative act of acting reveals a wound which has been incarnated in man, which may just the same be called the extraordinary gift of acting on stage. The gift of acting. In English, the word gift means present. ${ }^{5}$ In German, on the other hand, Gift means something toxic. Now, if we cross over the German and the English meaning of the word, danger and gain are crossed over, fear and joy, the disturbing and the fruitful. There happens a paradox encounter, a joyful shock, a shocking joy. One might say-perhaps even literally — that acting on stage by its highest demand makes actors/actresses subject to some "anthropological change" (Agamben 1999b, 260), in the course of which one must leave oneself to the dynamic process of transformation. The intensity of this process does neither spare any of those weaknesses nor any of those clichés all of us are full of. They are there, without exception, to our surprise even those we believed to be free of. Suddenly all of what up until now has been unseen and covered breaks into the open, takes us to a limit. Free will as an actor collapses, as we might have it pointedly. In terms of the cabaret: free will loses its stand, it becomes impotent, it is brought to its knees and sinks to the floor. There it is lying, grasping for breath. No help, nowhere. To have it more seriously and to repeat the event like a spiral: what happens does not depend on the actor/actress him/herself as an "object" nor is it a part of him/herself as a "subject" any longer. What in our everyday lives we commonly call our "property", the bastion of our identity, of our being a person, must be given up on. The subject somewhat "dies". Or, to have it more precisely, there happens a state of "dying", a mutation. The process may definitely be described this way. There appears something alien, unknown, something which cannot be perceived but appears nevertheless. Life as itself? Yes, maybe this way: for moments there appears a specific, at the same time impersonal, undefined life during the unique event of acting.

Is it not that by such a rare event-to have it in Deleuze's terminology-the plane of immanence presents itself where (a) life liberates itself by the never-ending desire to create itself? Life as a shapeless, self-organising process, constantly becoming qualitatively more differentiated out of itself? ${ }^{6}$ Then at theatre the art of mutating and liberating life would gain power and significance. Metamorphosis and not mimesis would be the predominant task of actors/actresses and the crucial event of acting on stage. 
Of course, theatre is tied and connected to the problems and questions of mimesis and the fact of repetition. Usually, theatre performances do not happen once but repeatedly, and repetition is highly demanding, for as a perfect, mechanical repetition it is insufficient. Such a way of acting may be masterly and impressive. Of course. But the source of creativity is the exciting repetition of the radical openness of life itself, when the grammatical categories of subject and object, of agent and patient, can no longer be distinguished. Then the comfort zone of personality only appears as the mask of the person-with nothing behind it. Maybe this is when the mask of Dionysus appears? The god Dionysus, whose cultic rituals are considered the origin and driving force of the development of Greek theatre and who is connected to the thrill of ecstasy, to delirium and death.

Precisely at theatre, which has such a fixation about person and personality, by the event of creativity acting on stage makes some impersonal yet unique life flash up which has nothing to do with fame, nothing to do with the glimmering hype of publicity. Mutation may become experientable, which Nietzsche would perhaps describe as a dancing star. This is the beautiful anachronism of this corrupt and wonderful art.

Of course, theatre allows for quite a number of other interpretations with different qualities. But I am convinced that the most remarkable event on stage, the crucial factor for its quality, is the loss of being a person, the loss of subjectivity, the loss of the first-person position. Actors/actresses may be violently attacked by this, because it makes the disconcerting flash up within ourselves. It is like tightrope walking without a safety net. However, is this not, like at the circus, the greatest attraction of acting, both for actors/actresses and audience, because the danger of falling down is so obvious? Even if this self-transgression is not expressed by words and stays unconscious, it works subcutaneously and provides acting with that inspiration and thrill which cannot be produced, cannot be made, but must successfully happen, must be successful out of itself. Always on the edge, looking into the abyss. Toying with falling into the abyss. A thrilling spectacle. Actors/actresses get in a state when the look of everyday life starts tumbling because suddenly life opens up by its immanent dimension and allows for looking at the passage from life to death. This then would be an event of the art of acting as the most fragile and intimate bond between performers and audience.

Perhaps sometimes theatre is actually like this, and because all of us are mortal we may then even understand that such a unique event of acting on stage "is a moment that is only that of $a$ life playing with death" (Deleuze 2001, 28).

Such an event is rare at theatre. Unique. A feast, happening beyond the categories of mishap and tragedy, even if the stories told on stage are full of it. Is it not that rather it liberates from the 
categories of good and evil, of pain and loss, of resentment and thirst for revenge? Is it not that it generates clear joy and generosity? Fundamental benevolence? Affirmation? Is it not that from this event there indeed develops something like an "anthropological mutation" by which both actors/actresses and audience are grasped? Even if this event just flashes up for a moment and soon fades away in everyday life. Is it not that it signals an ethical appeal concerning the question of what and how life may have become once?

Liberated from oneself to oneself by way of a memento mori by the act of creativity. Perhaps this is how one's own relation to the world is newly defined by way of the "death of subjectivity". A relation which need not be exclusively based on fear but may as well be experienced as an encouraging, promising openness. Actors/actresses experience themselves as being liberated into the widest potential of their possibilities, and that not only as a prospect in the sense of a promise concerning a distant future but as an immediately kept promise, kept during the time of acting on stage. Here and now. Immanent.

Id est: according to Aristotle, fear and compassion are the classical categories of catharsis at theatre. However, could the plane of immanence liberating itself, could the liberation of the immanent dimension of life be interpreted as the cathartic effect of theatre? Would it not result in passion and joy of the always renewing dimension of existence? Of its still undeveloped possibilities following at our heels, like our own shadows?

\section{To Conclude: A Life...}

Theatre is full of stories. Many cultures are full of stories. That is why, to conclude my considerations, I would like to quote a short passage from Charles Dickens's Our Mutual Friend, a passage Gilles Deleuze refers to in his last text Immanence: A Life... (Deleuze 2001, 28-29). By the example of a concrete story it once again illustrates, one might even say dramatizes, the event of the act of creativity on stage we have been talking about so far. It is the story of Mr. Riderhood, a predator and creep who, after having been saved from drowning, is now hovering between life and death:

\footnotetext{
No one has the least regard for the man: with them all, he has been an object of avoidance, suspicion and aversion; but the spark of life within him is curiously separable from himself now, and they have a deep interest in it, probably because it is life, and they are living and must die. [...] See! A token of life! An indubitable token of life! [...] He is struggling to come back. Now, he is almost here, now he is far away again. Now he is struggling harder to get back. And yet-like us all, when we swoon-like us all, every day of our lives when we wake-he is instinctively unwilling to be restored to the consciousness of this existence, and would be left dormant, if he could. (Dickens 1997, 419-420)
} 
${ }^{1}$ This article has been realized in the context of the research project "Artist-Philosophers. Philosophy AS Artsbased Research" funded by the Austrian Science Fund (FWF): AR275-G21 in line with the programme for artsbased research (PEEK).

2 See: Spinoza and his concept of parallelism: "The order and connection of ideas is the same as the order and connection of things" (cf. Spinoza 2000, 117 [2p7]). Deleuze: "Dualism is therefore only a moment, which must lead to a re-formation of a monism" (Deleuze 1998, 29), as well as Jean-Luc Nancy Corpus (2008).

${ }^{3}$ For Plato the body is a constant obstacle for the soul: "[T] he lovers of learning are aware that when philosophy takes over their soul, the soul really is bound thoroughly in the body and stuck to it, and is forced to consider the real things trough it as if through a cage, and not on its own through itself, and that it drifts in utter ignorance" (Plato 2011, 74 [82d-e]).

${ }^{4}$ Friedrich Nietzsche: "[...] there is no 'being' behind doing, effecting, becoming; 'the doer' is merely a fiction added to the deed-the deed is everything" (Nietzsche 1989, 45).

5 Derrida refers to the great number of meanings of the German word "Gift" (cf. Derrida 1992, for example 36, 81). And for the gift in Derrida, see also Derrida (1995).

${ }^{6}$ See Gilles Deleuze and Felix Guattari: "There are only relations of movement and rest, speed and slowness between unformed elements, or at least between elements that are relatively unformed, molecules and particles of all kinds. There are only haecceities, affects, subjectless individuations that constitute collective assemblages. [...] We call this plane, which knows only longitudes and latitudes, speeds and haecceities, the plane of consistency or composition (as opposed to a plan(e) of organization or development)" (Deleuze and Guattari 1987, 266).

\section{Works Cited}

Agamben, Giorgio. 1999a. "Absolute Immanence." In Potentialities: Collected Essays in Philosophy, edited and translated by Daniel Heller-Roazen, 220-242. Stanford: Stanford University Press.

1999b. "Bartelby or On Contingency." In Potentialities: Collected Essays in Philosophy, edited and translated by Daniel Heller-Roazen, 243-271. Stanford: Stanford University Press.

Deleuze, Gilles, and Félix Guattari. 1987. A Thousand Plateaus. Translated by Brian Massumi. Minnesota: University of Minnesota Press.

Deleuze, Gilles. 1998. Bergsonism. Translated by Hugh Tomlinson and Barbara Habbererjam. New York: Zone Books.

2001. Pure Immanence: Essays on A Life. Translated by Anne Boyman. New York: Zone Books.

Dickens, Charles. 1997. Our Mutual Friend. Hertfordshire: Wordsworth Edition.

Derrida, Jacques. 1992. Given Time: I. Counterfeit Money. Translated by Peggy Kamuf. Chicago: University of Chicago Press.

1995. The Gift of Death. Translated by David Wills. Chicago: University of Chicago Press.

Nancy, Jean-Luc. 2008. Corpus. Translated by Richard A. Rand. New York: Fordham University Press.

Nietzsche, Friedrich. 1989. On the Genealogy of the Morals. Translated by Walter Kaufmann and R.J. Hollingdale. New York: Vintage Books.

Plato. 2011. "Phaedo." In Meno and Phaedo, edited by David Sedley and Alex Long, translated by Alex Long, 42116. Cambridge and New York: Cambridge University Press.

Spinoza, Baruch de. 2000. Ethics. Edited and translated by G.H.R. Parkinson. Oxford: Oxford University Press. 
Since 1989 Susanne Valerie Granzer has been a Professor of the artistic discipline of the performing arts at the University of Music and Performing Arts Vienna, Max Reinhardt Seminar.

She was trained for being an actress at the MRS in Vienna. Then, for 18 years she had important parts at Theater in der Josefstadt, Volkstheater Wien, Theater Basel, Düsseldorfer Schauspielhaus, Schauspielhaus Frankfurt am Main, Schillertheater Berlin and Burgtheater Wien. Parallel she studied philosophy at Goethe-Universität Frankfurt am Main and the University of Vienna. Doctorate in 1995.

In 1997, together with the philosopher Arno Böhler, she founded wiener kulturwerkstätte GRENZ_film. Many "Philosophy on Stage" lecture performances. Co-founder of BASE (research centre for artistic research und artsbased philosophy, India) and the head of the residence programme there.

FWF research projects (as a cooperation partner): 2005-2007 "Materialität und Zeitlichkeit performativer Sprechakte" (P17600). 2010-2013 "Korporale Performanz/Generating Bodies" (TRP12-G21), 2014-2017 „ArtistPhilosophers. Philosophy AS Arts-based-research" (AR 275-G21). Publications (selection): Schauspieler außer sich. Exponiertheit und performative Kunst, Transcript Verlag, Bielefeld März 2011, second edition 2014. Actors and the Art of Performance. Under Exposure, Palgrave Macmillan 2016.

(c) 2017 Susanne Valerie Granzer

cc) (i) (2) Except where otherwise noted, this work is licensed under a Creative Commons Attribution-

(c) Non No sa Nonmercial-ShareAlike 4.0 International License. 